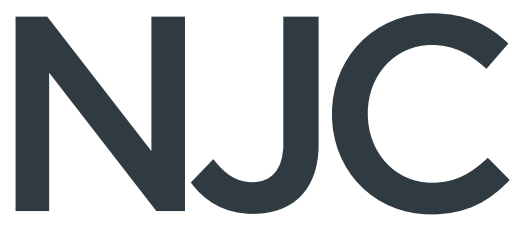

A journal for new directions in chemistry

New Journal of Chemistry rsc.li/njc
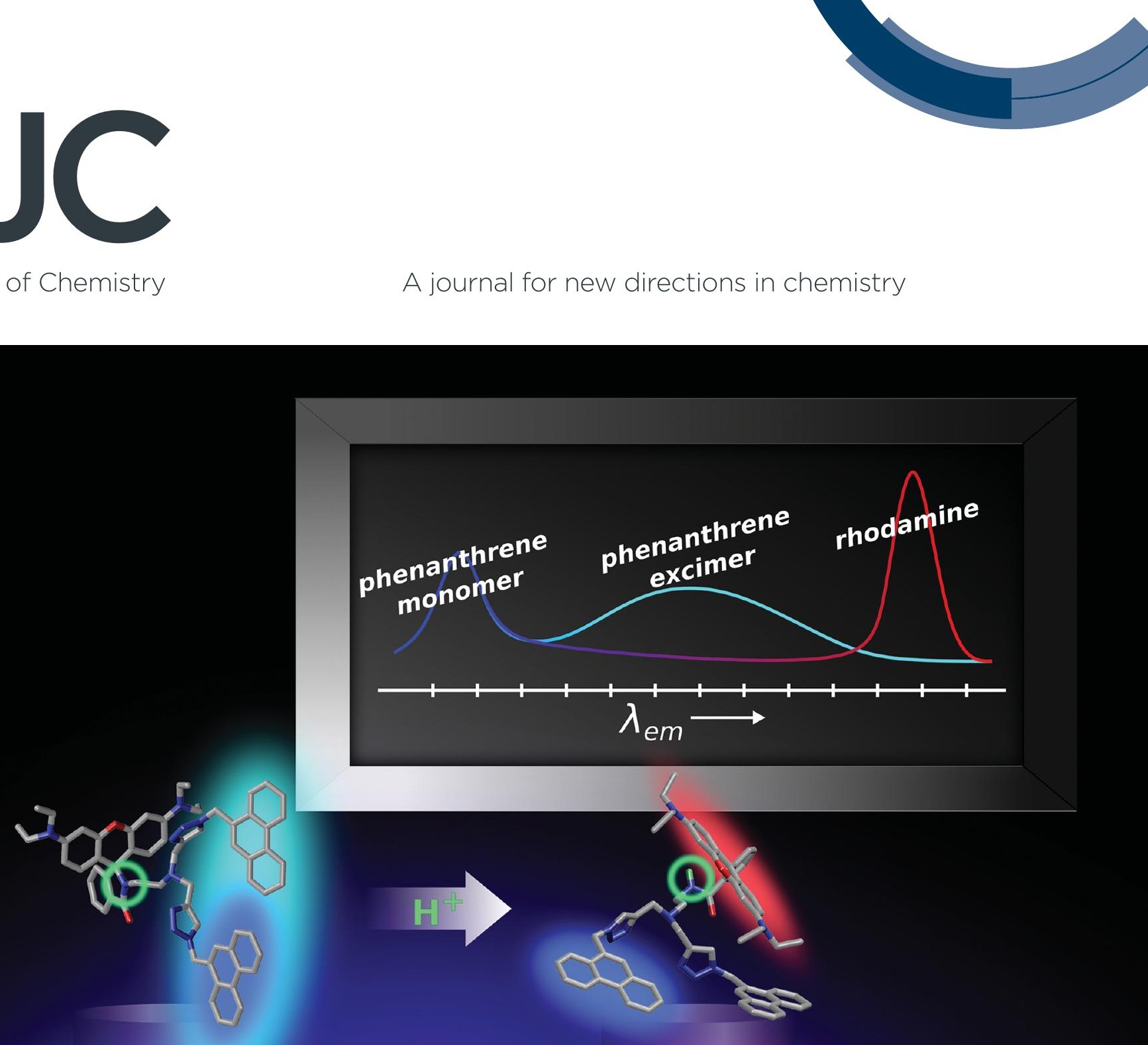
Check for updates

Cite this: New J. Chem., 2021. 45,13755

Received 31st March 2021 Accepted 8th June 2021

DOI: $10.1039 / d 1 n j 01573 g$

rsc.li/njc

\title{
Synthesis and spectroscopic characterization of a fluorescent phenanthrene-rhodamine dyad for ratiometric measurements of acid $\mathrm{pH}$ values $\dagger$
}

\author{
Priyanka Srivastava, (D) *a Paul Christian Fürstenwerth, ${ }^{a}$ Jan Felix Witte (D) ${ }^{b}$ and \\ Ute Resch-Genger iD *a
}

\begin{abstract}
We present the rational design, synthesis and spectroscopic characterization of a novel dual excitation, three color emitting, $\mathrm{pH}$-responsive fluorescent probe consisting of two phenanthrene and one rhodamine $B$ units linked by click chemistry. The rhodamine moiety, excitable at $\lambda_{\mathrm{Ex}}=315 \mathrm{~nm}$ and at $\lambda_{\mathrm{Ex}}=560 \mathrm{~nm}$ in its ring-opened form, provides the $\mathrm{pH}$-responsive fluorophore, while the $\mathrm{pH}$-insensitive phenanthrene, excited at $\lambda_{\mathrm{Ex}}=315 \mathrm{~nm}$, serves as inert internal reference, The presence of two phenanthrene moieties enables a blue monomer and a blueish green excimer emission at $351 \mathrm{~nm}$ and $500 \mathrm{~nm}$, respectively. Opening of the rhodamine B spirolactam ring at an acidic pH below $5.0\left(\mathrm{p} K_{\mathrm{a}}=\right.$ $2.59 \pm 0.04)$ switches on its emission at $580 \mathrm{~nm}$. Simultaneously, the phenanthrene excimer emission decreases caused by a change in orientation of the phenanthrene units, while the monomer emission is barely affected. This sensor design enables ratiometric measurements in the low acidic $\mathrm{pH}$ range utilizing the intensity ratios of the rhodamine $B$ and phenanthrene excimer emission at $580 \mathrm{~nm}$ and $500 \mathrm{~nm}$. Alternatively, also the intensity ratios of the rhodamine $B$ and the phenanthrene monomer emission could be exploited or the sum of the phenanthrene monomer and excimer fluorescence. To the best of our knowledge, this is the first report of ratiometric sensing utilizing such a versatile type of tricolor emissive dyad probe bearing phenanthrene moieties and showing phenanthrene monomer and excimer emission.
\end{abstract}

\section{Introduction}

$\mathrm{pH}$ is one of the most relevant parameters in the life and material sciences indicating e.g. proper functioning of cells, diseases like inflammation and cancer, and corrosion processes. ${ }^{1}$ Also, $\mathrm{pH}$ regulates several metabolic pathways that include endocytic processes, signaling, apoptosis and cell defense mechanisms. ${ }^{2-5}$ An acidic environment is for example essential for the functioning and activation of various enzymes and process involved in protein degradation, and organelles like lysosomes ( $\mathrm{pH} 4.5-5.5)$ and endosomes ( $\mathrm{pH}$ 4.5-6.8) have an acidic $\mathrm{pH}$ for proper functioning. ${ }^{6-12}$ Abnormalities in intracellular $\mathrm{pH}$ can affect the various cell functions, like muscle contraction and relaxation, ${ }^{6}$ apoptosis, ${ }^{13,14}$ ion transport, and cellular homeostasis and signal or accompany several diseases including cancer and neurodegenerative disorders. ${ }^{6,13,14}$

\footnotetext{
${ }^{a}$ Division Biophotonics, Federal Institute for Materials Research and Testing (BAM), Richard-Willstatter-Strasse, 11, 12489 Berlin, Germany. E-mail: priyanka.srivastava@bam.de, ute.resch@bam.de

${ }^{b}$ Institute of Chemistry and Biochemistry, Freie University Berlin, Kaiserswerther Str. 16-18, 14195 Berlin, Germany

$\dagger$ Electronic supplementary information (ESI) available: Synthesis, characterization of and photophysical data. See DOI: 10.1039/d1nj01573g
}

pH can be measured electrochemically or optically, ${ }^{15,16}$ in the latter case utilizing an optical probe, i.e., a sensor molecule or a chemodosimeter, that signals changes in $\mathrm{pH}$ by changes in its absorption $^{1}$ and/or fluorescence properties. ${ }^{17-20}$ Very sensitive $\mathrm{pH}$ measurements with a high spatiotemporal resolution can be best done with pH-responsive molecular or nanoscale optical probes ${ }^{20-26}$ which can be also exploited for intracellular pH studies. ${ }^{1}$ Suitable $\mathrm{pH}$-responsive probes can be rationally designed utilizing different signaling mechanisms such as (intramolecular) charge transfer, photo-induced electron transfer (PET), or energy transfer $(\mathrm{ET})^{27-30}$ processes, that provide the basis for reversible $\mathrm{pH}$-induced changes in the spectral and/ or intensity of the probe's absorption and/or fluorescence. ${ }^{2}$ Alternatively, a chemical reaction to form an optically detectable species can be exploited. ${ }^{31}$ In addition, suitable probes should be chemically stable, show high molar absorption coefficients, and high fluorescence quantum yields as a prerequisite for a high sensitivity. Moreover, they should reveal no or only very little interferences with other analytes such as metal ions typically present in biological systems. As fluctuations of the excitation light source and changes in probe concentration induced by, e.g. photobleaching can directly affect measured 
fluorescence intensities, pH-responsive probes are favored that enable ratiometric $\mathrm{pH}$ measurements. This can be realized with molecules showing a dual emission which is, however, rare, ${ }^{32-35}$ or which exhibit strong $\mathrm{pH}$-induced spectral changes in absorption as revealed e.g., by the near-infrared emissive $\mathrm{pH}$-probe Cypher $5 .^{36,37}$ Alternatively, two spectrally distinguishable fluorophores can be combined to a ratiometric sensor. This can be achieved with bichromophoric or dyad-type molecular probes, ${ }^{32-35}$ that are, however, challenging to synthesize, or with the aid of nanoparticles doped and labeled with two different fluorophores. ${ }^{38}$

A dye class that is particularly well suited for the design of fluorescent probes are the rhodamines. Also, rhodamines can reveal an acid-induced ring opening mechanism occurring at $\mathrm{pH}$ values of $\sim 5-4$ that provides the basis for OFF-ON fluorescence switching. ${ }^{26,31}$ Such an OFF-ON or ON-OFF signaling mechanism, however, does not enable ratiometric, i.e., self-referenced fluorescence measurements. In order to utilize this acidic ring opening mechanism of rhodamine dyes for the design of a ratiometric sensor for $\mathrm{pH}$ measurements, ${ }^{25-31}$ we designed a novel dyad probe by combining a pH-responsive rhodamine $\mathrm{B}$ derivative with two pH-inert phenanthrene fluorophores in one molecule. Phenanthrene was used here since it can form emissive excimers and can provide a blue monomer and a green excimer emission at the same time which can be both used as a reference of the pH-responsive rhodamine emission. Thereby, the dyad probe is always fluorometrically detectable even when the rhodamine fluorophore is in its non-emissive spirolactam form. In the following, we present the synthesis of this first example of a bichromophoric, three color-emissive ratiometric $\mathrm{pH}$ probe and its spectroscopic properties as well as selectivity studies.

\section{Results and discussion}

\section{Design and synthesis of the $\mathrm{pH}$-sensitive tri-color emissive dyad 8}

The synthesis of the bichromophoric $\mathrm{pH}$ sensor $\mathbf{8}$, obtained from two phenanthrene and one rhodamine B units via Click chemistry, is summarized in Fig. $1 .^{39}$ A detailed description of the preparation procedures of the different intermediates and the challenging purifications is given in the (ESI $\dagger$ ). The synthesis of the azide derivative of phenanthrene starting from phenanthrene carboxaldehyde $\mathbf{1}$ involves three steps. First, the carboxaldehyde phenanthrene derivative $\mathbf{1}$, was reduced to its hydroxy derivative 2 , then a chlorine substituent was introduced by reaction with $\mathrm{SOCl}_{2}$ yielding 3 , and in next step, substituted by an azide group by reaction with $\mathrm{NaN}_{3}$ in dimethylformamide providing 4. The propargyl derivative of rhodamine $\mathrm{B}$, compound 7 , was prepared in two steps. In the first step, rhodamine $\mathrm{B}$, i.e., 5, was reacted with ethylene diamine in ethanol to form the spirolactam ring derivative $\mathbf{6}$ of rhodamine B with one free amino group. In the second step, the free amine group of 6 reacted with two moles of propargyl bromide to compound 7. Compound 7 was purified by column chromatography using neutral aluminium oxide to give a faintly yellow resin. Finally, two phenanthrene azide 4 molecules and

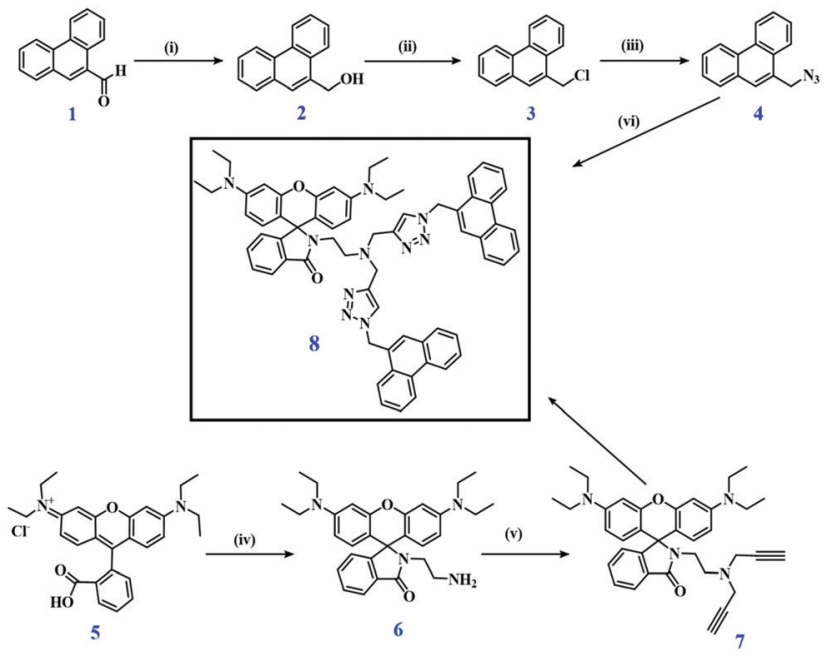

Fig. 1 Synthetic scheme of $\mathrm{pH}$-responsive dyad 8 (i) $\mathrm{NaBH}_{4} /$ methanol/RT (ii) $\mathrm{SOCl}_{2} / \mathrm{DCM} / \mathrm{RT}$ (iii) $\mathrm{NaN}_{3} / \mathrm{DMF} / 100{ }^{\circ} \mathrm{C}$ (iv) ethylene diamine/ethanol/ reflux (v) propargyl bromide $/ \mathrm{K}_{2} \mathrm{CO}_{3} / \mathrm{THF} /$ reflux (vi) $\mathrm{CuSO}_{4} \cdot 5 \mathrm{H}_{2} \mathrm{O}$, sodium ascorbate/ethanol-water/70 ${ }^{\circ} \mathrm{C}$.

one molecule of propargyl derivative 7 were coupled by a Click reaction in the presence of $\mathrm{CuSO}_{4}$ and sodium ascorbate in an ethanol water mixture [36] to form $\mathrm{pH}$ sensor 8 with a yield of $50 \%$. Comp 8 was purified by column chromatography on neutral $\mathrm{Al}_{2} \mathrm{O}_{3}$ using a mixture of hexane, ethyl acetate, and methanol as an eluent. Purified 8 was characterized by ${ }^{1} \mathrm{HNMR}$, ${ }^{13} \mathrm{C}$ NMR, and ESI-MS analysis (Fig. S1-S10, ESI $\dagger$ ).

Dyad 8 is designed to exploit the $\mathrm{pH}$-induced ring opening mechanism of the rhodamine spirolactam unit, ${ }^{26,40-45}$ that turns this initially colorless and non-emissive moiety into a strongly absorbing pink fluorophore, and combine this ON/OFF $\mathrm{pH}$-sensing with the $\mathrm{pH}$-inert fluorescence of phenanthrene. Phenanthrene was used as this dye can form emissive excimers spectrally distinguishable from the monomer emission, Excimer formation requires the interaction of two neighboring phenanthrene molecules that is favored by the chemical structure of $\mathbf{8}$. Thereby, fluorescence intensity-based sensing is combined with the blue monomer and green excimer emission of phenanthrene for single wavelength excitation. Our ratiometric approach for $\mathrm{pH}$ sensing utilizes the ratio of the two emission bands of the dyad observed upon excitation at $315 \mathrm{~nm}$, measured in the wavelength range of $420-540 \mathrm{~nm}$ and $540-620 \mathrm{~nm}$.

\section{Photophysical behavior of dyad 8}

The absorption spectra of dyad $\mathbf{8}$ in dichloromethane (DCM), tetrahydrofuran (THF), and ethanol (EtOH) reveal absorption bands at $298 \mathrm{~nm}$ and $315 \mathrm{~nm}$ originating from the phenanthrene and rhodamine moieties, respectively. The corresponding emission spectra recorded at an excitation wavelength $\left(\lambda_{\mathrm{Ex}}\right)$ of $315 \mathrm{~nm}$ exhibit phenanthrene monomer and excimer emission bands (Fig. 2a and b). At neutral or basic $\mathrm{pH}$ to the colorless and non-emissive spirolactam form of rhodamine $\mathrm{B}$ derivative $\mathbf{6}$, absorbing below $350 \mathrm{~nm}$, is fluorometrically silent. The phenanthrene excimer fluorescence is most pronounced in DCM where the monomer emission is absent. In THF, the excimer emission still exceeds the 

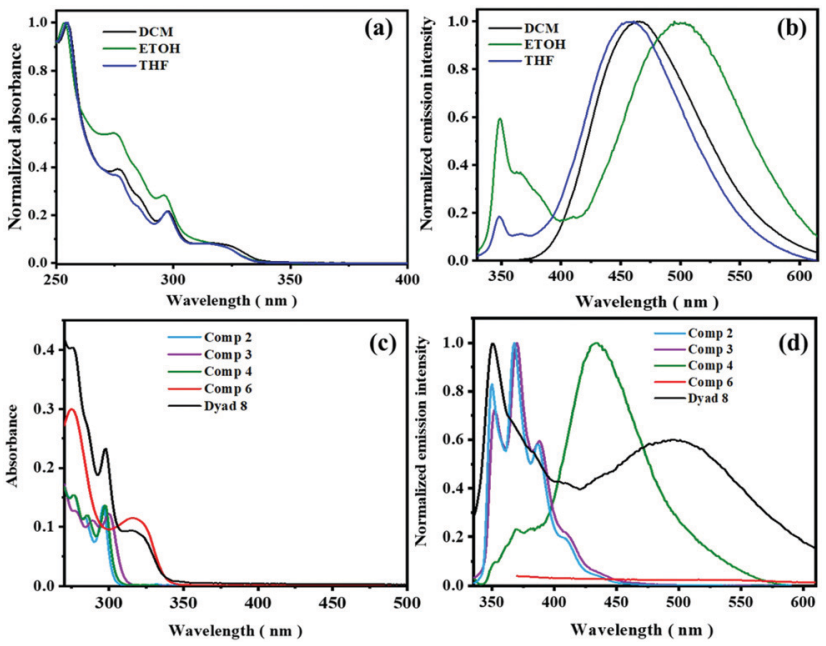

Fig. 2 (a) Normalized absorption and (b) normalized emission spectra of dyad $8(5 \mu \mathrm{M})$ in different solvents $\left(\lambda_{\mathrm{Ex}}=315 \mathrm{~nm}\right.$; DCM, THF, EtOH). (c) Absorption $(8.0 \mu \mathrm{M})$ and $(\mathrm{d})$ normalized emission spectra of compounds $\mathbf{2}$, 3, 4, 6, and dyad 8 in $\mathrm{THF}-\mathrm{H}_{2} \mathrm{O}$ mixtures $(1: 1)$ in a Britton-Robinson (B-R) buffer (25 mM).

weak monomer emission, and in ethanol, excimer and monomer fluorescence are equally intense (Fig. 2a, b and Fig. S11, ESI †). For some phenanthrene derivatives, a modest solvent dependence of the optical properties was reported in low or medium polar solvents similar to some reports on the spectroscopic features of pyrene and naphthalene. ${ }^{46,47}$ Our dyad molecule reveals shifts in emission in DCM and THF similar to reports from other research groups whereas the red shift observed in the highly polar solvent ethanol is unusual. ${ }^{48}$ The spectral position of the monomer emission of the dyad is independent of solvent polarity while the spectral position of the excimer fluorescence undergoes modest changes for low and medium polar solvents and a strong red shift in highly polar protic solvents like ethanol as shown in Table 1. The absorption spectrum of compound $\mathbf{8}$ is barely affected by solvent polarity.

Table 1 Absorption maxima $\left(\lambda_{\max , A b s}\right)$ and emission maxima $\left(\lambda_{\max , \mathrm{Em}}\right)$ of pyrene (used as quantum yield standard; quantum yield value taken from ref. 49 and 50) and compounds $\mathbf{2}, \mathbf{3}$, and $\mathbf{4}$ as well as dyad $\mathbf{8}$ in different solvents. all phenanthrene derivatives are excited at $300 \mathrm{~nm}$. The absorbances at the excitation wavelengths were typically between 0.1 and 0.2 . The fluorescence quantum yields of the phenanthrene unit in dyad 8 are considerably underestimated in all cases upon excited at $315 \mathrm{~nm}$ as the absorbance at this wavelength contains also considerable contributions from the non-emissive ring-closed rhodamine unit as shown in Fig. $2 \mathrm{c}$

\begin{tabular}{|c|c|c|c|c|c|}
\hline Sample & Solvent & $\begin{array}{l}\text { Refractive } \\
\text { index }\end{array}$ & $\begin{array}{l}\lambda_{\max , \mathrm{Abs}} / \\
\mathrm{nm}\end{array}$ & $\begin{array}{l}\lambda_{\max , \mathrm{Em}} / \\
\mathrm{nm}\end{array}$ & $\begin{array}{l}\text { Quantum } \\
\text { yield } \Phi\end{array}$ \\
\hline Pyrene $^{49,50}$ & Cyclohexane (CH) & 1.42662 & 333 & 384 & 0.320 \\
\hline Compound 2 & THF-water $(1: 1)$ & 1.3801 & 298 & 367 & 0.214 \\
\hline Compound 3 & THF-water $(1: 1)$ & 1.3801 & 301 & 370 & 0.034 \\
\hline Compound 4 & THF-water $(1: 1)$ & 1.3801 & 296 & 434 & 0.067 \\
\hline Dyad 8 & THF-water $(1: 1)$ & 1.3801 & 315 & 351,500 & 0.026 \\
\hline Dyad 8 & THF-water $(2: 1)$ & 1.3801 & 315 & 350,499 & 0.039 \\
\hline Dyad 8 & THF-water $(1: 2)$ & 1.3801 & 315 & 353,503 & 0.024 \\
\hline Dyad 8 & DCM & 1.4241 & 315 & 466 & 0.141 \\
\hline Dyad 8 & Ethanol & 1.36 & 315 & 501 & 0.025 \\
\hline Dyad 8 & THF & 1.4072 & 315 & 458 & 0.086 \\
\hline
\end{tabular}
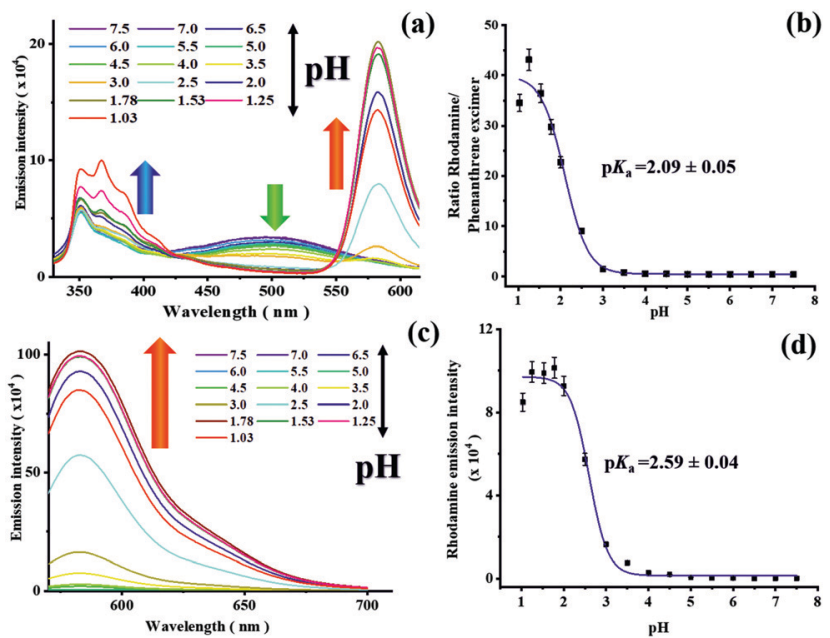

(b)

Fig. 3 Emission spectra of dyad $8(5 \mu \mathrm{M})$ at different $\mathrm{pH}$ values varied from 7.5 to 1.0 (a) excitation at $\lambda_{\mathrm{Ex}}=315 \mathrm{~nm}$ and (c) excitation at $\lambda_{\mathrm{Ex}}=560 \mathrm{~nm}$, respectively. Calculation of the $\mathrm{p} K_{\mathrm{a}}$ was done by a sigmoidal fit of (b) a ratiometric approach (readout of $I_{582} / /_{500} \mathrm{~nm}$ at $\lambda_{E x}=315 \mathrm{~nm}$ ) and (d) for the emission intensity at $580 \mathrm{~nm}$ recorded at $\lambda_{\mathrm{Ex}}=560 \mathrm{~nm}$, thereby solely exciting the rhodamine unit. All measurements were done in $\mathrm{THF}-\mathrm{H}_{2} \mathrm{O}$ solvent mixtures $(1: 1)$ in a B-R buffer $(25 \mathrm{mM})$.

The absorption and emission spectra of all compounds synthesized for the preparation of dyad $\mathbf{8}$ are provided in Fig. $2 \mathrm{c}$ and $\mathrm{d}$ and their quantum yields are given in Table 1. Further studies of this dyad were performed in a mixture of $50 \%$ THF and $\mathrm{H}_{2} \mathrm{O}$ in a Britton Robinson (B-R) buffer for $\mathrm{pH}$ control (ESI $\dagger$ ). The absorption spectra of dyad 8 reveal absorption bands at $298 \mathrm{~nm}$ and $315 \mathrm{~nm}\left(\varepsilon=11430 \mathrm{M}^{-1} \mathrm{~cm}^{-1}\right.$; Fig. S13, ESI $\dagger)$ and the emission spectra $\left(\lambda_{\mathrm{Ex}}=315 \mathrm{~nm}\right)$ exhibit two bands at $351 \mathrm{~nm}$ and $500 \mathrm{~nm}$ (overall quantum yield of both phenanthrene emission bands $\Phi=0.026 ; 65 \%$ and $35 \%$ contribution from phenanthrene excimer and monomer emission) as shown in Fig. 3. Please not here that the fluorescence quantum yields of the phenanthrene unit in dyad $\mathbf{8}$ are considerably underestimated upon excitation at $300 \mathrm{~nm}$ as the absorbance at this wavelength contains also considerable contributions from the non-emissive ring-closed rhodamine unit as shown in Fig. 2c.

\section{pH studies of dyad 8}

The absorption and emission properties of dyad, $8(5 \mu \mathrm{M})$ were studied in the $\mathrm{pH}$ range of 7.5 to $1.0 \mathrm{in} \mathrm{THF}-\mathrm{H}_{2} \mathrm{O}$ mixtures $(1: 1)$ in a Britton Robinson buffer ${ }^{51}$ using excitation wavelengths of $315 \mathrm{~nm}$ (phenanthrene and rhodamine absorption) and $560 \mathrm{~nm}$ (rhodamine absorption), thereby examining also the $\mathrm{pH}$-dependence of the emission behavior of the different fluorophores constituting the dyad sensor. Excitation at $315 \mathrm{~nm}$ results in two emission bands at $\lambda_{\mathrm{Em}}=351 \mathrm{~nm}$ and $\lambda_{\mathrm{Em}}=500 \mathrm{~nm}$ at $\mathrm{pH} 7.5$ originating solely from the phenanthrene moieties as the rhodamine exists in its ring-closed form under these conditions that is non-emissive. A change in $\mathrm{pH}$ from 7.5 to 4.5 barely affects the intensity of both the phenanthrene monomer and excimer emission indicating the suitability of phenanthrene as $\mathrm{pH}$-inert reference dye. A further decrease of 
Table 2 Fluorescence quantum yields of dyad 8 and compound 6 at pH 7.0 and pH 2.0 with pyrene (pyrene in cyclohexane: $\Phi=0.32 ;$ ref. 49 and 50) and rhodamine B (rhodamine in ethanol: $\Phi=0.7$; ref. 53 ) as quantum yield standards determined at different excitation wavelengths. The absorbances of the samples at the excitation wavelength were between 0.1 and 0.2 . The emission range given equals the emission range used for integration of the fluorescence bands

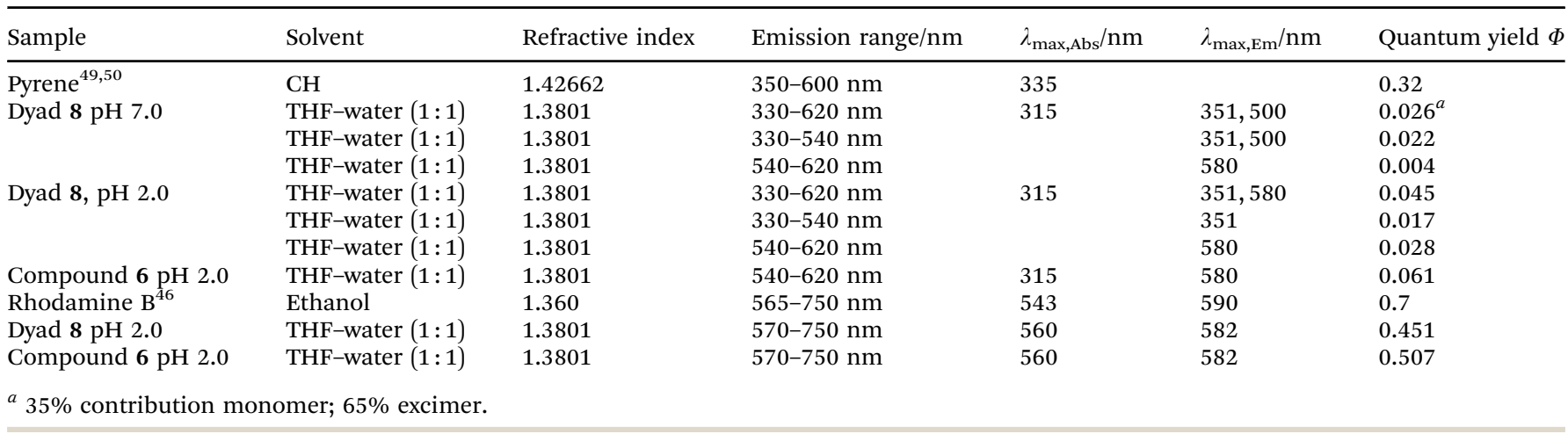

the $\mathrm{pH}$ from 4.5 to 2.0 , however, leads to a diminution particularly of the phenanthrene excimer emission at $500 \mathrm{~nm}$ and the appearance of a new fluorescence band at $582 \mathrm{~nm}$ corresponding to the rhodamine $\mathrm{B}$ derivative with the open spirolactam ring (Table 2 and Fig. 4, Table S1, ESI $\dagger$ ). The intensity of this band further increases with decreasing $\mathrm{pH}$ (Fig. 3a and Fig. S14, ESI $\dagger$ ) and saturates at $\mathrm{pH} 1.78$. The ratiometric response $\left(I_{582} / I_{500} \mathrm{~nm}\right)$ of the fluorescence intensities of the rhodamine $\mathrm{B}$ and phenanthrene excimer of the dyad sensor at different $\mathrm{pH}$ yields a $\mathrm{p} K_{\mathrm{a}}$ as $2.09 \pm 0.05$ (Fig. $3 \mathrm{~b} ; \lambda_{\mathrm{Ex}}=315 \mathrm{~nm}$ ) by applying a dose response equation for the sigmoidal fit of the $\mathrm{pH}$ curve. ${ }^{52}$

The influence of $\mathrm{pH}$ on the spectroscopic properties of $\mathbf{8}$ was also assessed for an excitation wavelength of $560 \mathrm{~nm}$, where solely the rhodamine B moiety absorbs. At pH 7.5 the spirolactam rhodamine $\mathrm{B}$ derivative absorbs only at wavelengths

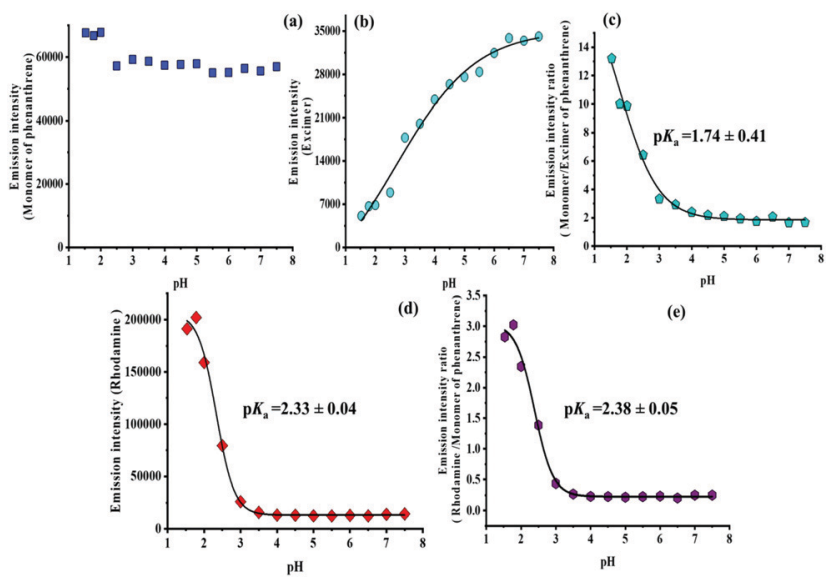

Fig. 4 Emission intensity changes of dyad $8\left(\lambda_{E x}=315 \mathrm{~nm}\right)$ as a function of $\mathrm{pH}$ shown for (a) the $351 \mathrm{~nm}$ emission of the phenanthrene monomer, (b) the $500 \mathrm{~nm}$ fluorescence of the phenanthrene excimer, (c) the intensity ratio of the phenanthrene monomer and excimer emission at $351 \mathrm{~nm}$ and $500 \mathrm{~nm}$, (d) the $582 \mathrm{~nm}$ rhodamine emission, and (e) the intensity ratio of the $582 \mathrm{~nm}$ rhodamine and the $351 \mathrm{~nm}$ phenanthrene monomer fluorescence. All measurements were done with dyad 8 dissolved in $\mathrm{THF}-\mathrm{H}_{2} \mathrm{O}$ mixtures $(1: 1)$ in a $B-R$ buffer $(25 \mathrm{mM})$.
$<350 \mathrm{~nm}$ (see Fig. 2, compound 6) and is not emissive. As the pH decreases further to pH 6.0, a new absorption band at about $560 \mathrm{~nm}$ appears and a new emission band at $582 \mathrm{~nm}$. The intensity of both bands is gradually enhanced at more acidic $\mathrm{pH}$ values (Fig. 3c). A further decrease of $\mathrm{pH}$ leads to a large fluorescence enhancement. The fluorescence quantum yield of the resulting ring opened rhodamine B amounts to $\Phi=0.45$ ( $\mathrm{pH}$ 2.0). The $\mathrm{p} K_{\mathrm{a}}$ value of the rhodamine system is calculated to $\mathrm{p} K_{\mathrm{a}}=2.59 \pm 0.04$ utilizing a dose response equation (Fig. $3 \mathrm{~d}$; rhodamine excitation at $560 \mathrm{~nm}$ ).

The $\mathrm{pH}$-dependence of the three different emission bands of dyad 8 observed upon $315 \mathrm{~nm}$ excitation was subsequently studied in more detail. The $\mathrm{pH}$-dependence of the emission bands at $351 \mathrm{~nm}, 500 \mathrm{~nm}$, and $582 \mathrm{~nm}$ is shown in Fig. 4 for the $\mathrm{pH}$ range of 7.5 to 1.5 . The monomer emission undergoes only minimum intensity changes up to a pH of 2.0 (Fig. 3 and $4 \mathrm{a}$ ) and can serve as a constant $\mathrm{pH}$-inert reference to monitor the changes exhibited either by the excimer fluorescence of phenanthrene at $500 \mathrm{~nm}$ (see Fig. 3 and $4 \mathrm{~b}$ ) or the rhodamine emission intensity at $582 \mathrm{~nm}$ (Fig. 3 and $4 \mathrm{~d}$ ). The intensity ratio of the phenanthrene monomer and excimer fluorescence (Fig. 4c) showed a $\mathrm{p} K_{\mathrm{a}}=1.74 \pm 0.41(351 / 500 \mathrm{~nm})$ while the intensity ratio (Fig. 4e) of the rhodamine emission at $582 \mathrm{~nm}$ and the phenanthrene monomer fluorescence at $351 \mathrm{~nm}$ revealed a $\mathrm{p} K_{\mathrm{a}}=2.38 \pm 0.05(582 / 351 \mathrm{~nm})$. A plot of the intensity of the $582 \mathrm{~nm}$ rhodamine emission excited at $315 \mathrm{~nm}$ as a function of $\mathrm{pH}$ gives a $K_{\mathrm{a}}=2.33 \pm 0.04$ (Fig. $4 \mathrm{~d}$ ).

The response time of dyad 8 to $\mathrm{pH}$ was determined by addition of dyad 8 to a THF-water solution of pH 2.0 (Fig. 5). The emission spectra of the dye measured immediately after addition ( $0 \mathrm{~min})$ showed a complete disappearance of the excimer emission. Subsequently, the rhodamine emission band at $582 \mathrm{~nm}$ started to appear and increased steadily in intensity with time. After 16 min, only marginal changes were observed, and the emission spectra reached constant values about at $20 \mathrm{~min}$. Hence, although the overall response time of dyad 8 for a complete ring opening is $20 \mathrm{~min}$. at $\mathrm{pH} 2.0$ as reflected by constant emission spectra resulting at this time, the appearance and growing in of the rhodamine emission started 


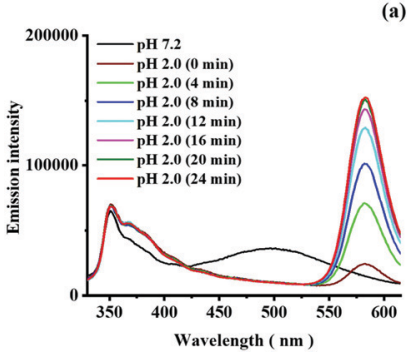

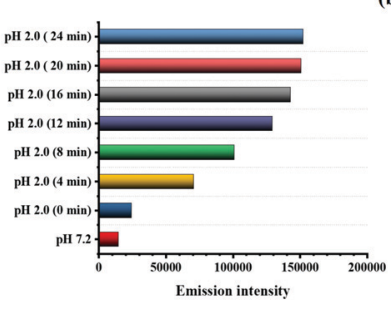

Fig. 5 (a) Emission spectra and (b) bar graph of the response time of the fluorescence of dyad $\mathbf{8}$ observed upon addition of dyad $\mathbf{8}$ to a $\mathrm{THF}-\mathrm{H}_{2} \mathrm{O}$ mixture (1:1) in B-R buffer ( $25 \mathrm{mM}$ ) of $\mathrm{pH} 2.0$; excitation $\lambda_{\mathrm{Ex}}$ was at $315 \mathrm{~nm}$ and the fluorescence intensity was recorded at an emission wavelength $\lambda_{\mathrm{em}}$ of $582 \mathrm{~nm}$. The emission spectra of dyad 8 were recorded every $4 \mathrm{~min}$. The data obtained at $\mathrm{pH} 7.2$, where no ring opening should occur, are included as control.

immediately upon dye-proton interaction. This principally provides the basis for shorter measurement times.

\section{Mechanistic studies and considerations}

As previously discussed, $\mathrm{pH}$ sensing with the rhodamine moiety utilized in dyad $\mathbf{8}$ is based upon the $\mathrm{pH}$-induced opening of the spirolactam ring of the rhodamine. This ring opening reaction at $\mathrm{pH}<5$ involves the protonation of the amino group of the xanthene core, which is signaled by the appearance of an absorption band at $560 \mathrm{~nm}$ responsible for the pink color of the dyad solution and an increasingly enhanced emission located at $582 \mathrm{~nm}$ (Fig. 7). The opening of the spiro-lactam ring simultaneously changes the distance and possibly also the orientation of the two phenanthrene units, which is reflected by a decrease of the phenanthrene excimer emission by about $66 \%$. Although phenanthrene itself is not sensitive to $\mathrm{pH}$ as demonstrated by us (Fig. S14, ESI $\dagger$ ), this also renders the phenanthrene excimer emission $\mathrm{pH}$-responsive at acidic $\mathrm{pH}$ values $\leq 4.5$ (Fig. $4 \mathrm{~b}$ ). The decrease in excimer emission automatically leads to an increase in the monomer emission of phenanthrene as shown in Fig. 3 (panel a) by about 23\% (Fig. S15, ESI $\dagger$ ). These changes barely affect the ratiometric readout of the sensor dyad. Moreover, by utilizing the sum of the monomer and excimer emission of phenanthrene as a reference for the $\mathrm{pH}$-dependent rhodamine emission, e.g. by using integral fluorescence intensities (integration of the rhodamine emission from $540 \mathrm{~nm}$ to $620 \mathrm{~nm}$; integration of the phenanthrene emission from $330 \mathrm{~nm}$ to $540 \mathrm{~nm}$ ) instead of intensity ratios measured at single wavelengths of $580 \mathrm{~nm}$ and $500 \mathrm{~nm}$, these effects can be considered.

Subsequently, we tried to quantify the contribution of the phenanthrene and rhodamine absorption to the dyad's absorption at $315 \mathrm{~nm}$ chosen as excitation wavelengths for ratiometric $\mathrm{pH}$ measurements. For this purpose, we compared the absorption and fluorescence excitation spectra of dyad $\mathbf{8}$ and compound $\mathbf{6}$ (Fig. S16, ESI $\dagger$ ). This comparison reveals a ratio of the absorption values at $315 \mathrm{~nm}$ and $560 \mathrm{~nm}$ at pH 2.0 of 2.9 for dyad 8 while for compound 6 which has only a rhodamine unit, this
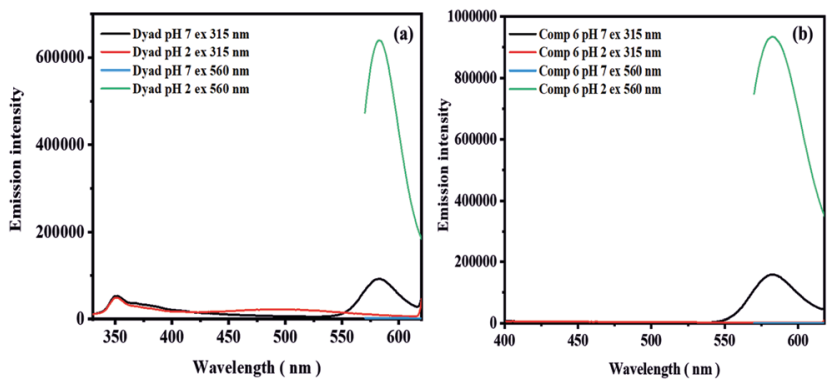

Fig. 6 Emission spectra recorded at excitation wavelength of $315 \mathrm{~nm}$ and $560 \mathrm{~nm}$ at $\mathrm{pH} 7.0$ and $2.0(3.3 \mu \mathrm{M})$ of (a) dyad 8 and (b) compound 6 in a $\mathrm{THF}-\mathrm{H}_{2} \mathrm{O}$ mixture $(1: 1)$ in $\mathrm{B}-\mathrm{R}$ buffer $(25 \mathrm{mM})$.

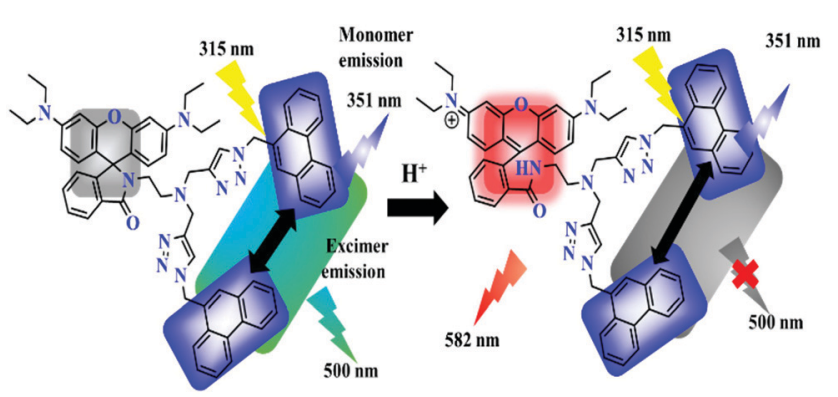

Fig. 7 The spirolactam and open ring derivative of the dyad $\mathbf{8}$.

ratio amounts to only 1.28 (Fig. S17, ESI $\dagger$ ). The emission intensity at $582 \mathrm{~nm}$ resulting upon excitation at $560 \mathrm{~nm}$ exceeds that observed upon excitation at $315 \mathrm{~nm}$ by a factor of $6.95 \mathrm{in}$ the case of dyad $\mathbf{8}$ as shown in Fig. 6 while for compound $\mathbf{6}$ a factor of 5.86 was obtained under similar experimental conditions. This difference between dyad 8 and compound $\mathbf{6}$ is ascribed to the presence of the two phenanthrene moieties in the dyad. When considering the fluorescence quantum yields of the $580 \mathrm{~nm}$ rhodamine emission band (wavelength range of 540-620 nm) excited at $315 \mathrm{~nm}$ and $560 \mathrm{~nm}$, the difference between the two emission ratios obtained at $580 \mathrm{~nm}$ of 1.3 correlates with the contribution of the phenanthrene moieties to the absorption of the dyad at $315 \mathrm{~nm}$. Similarly, we observed a 1.33-fold decrease in fluorescence quantum yield of the $580 \mathrm{~nm}$ band of the rhodamine (540-620 nm range) excited at $330 \mathrm{~nm}$ for dyad 8 in comparison to compound 6 lacking the phenanthrene units (Table 2).

In addition, we performed time-resolved fluorescence studies with dyad $\mathbf{8}$ and compound $\mathbf{6}$ at $\mathrm{pH}$ 2.0. The resulting fluorescence decay curves are shown in the ESI, $\uparrow$ in Fig. S18 and S19. Fitting these decay curves with biexponential decay kinetics provided fluorescence lifetimes $\tau$ of $1.71 \mathrm{~ns}(84 \%)$ and $1.66 \mathrm{~ns}(76 \%)$ for dyad 8 of the main decay components using a biexponential fit of the fluorescence decays obtained at excitation wavelengths of $330 \mathrm{~nm}$ and $510 \mathrm{~nm}$ (detection at $580 \mathrm{~nm}$ ) and fluorescence lifetimes $\tau$ of $1.63 \mathrm{~ns}$ (monoexponential fit) and $1.73 \mathrm{~ns}$ (84\%; main component) for compound 6 (biexponential) for excitation at $330 \mathrm{~nm}$ and $510 \mathrm{~nm}$ and detection at $580 \mathrm{~nm}$ (Fig. S18 and S19, ESI $\dagger$ ). The lifetimes are almost similar in the case of dyad $\mathbf{8}$ and compound 6 indicating the absence of electronic interaction between the rhodamine and phenanthrene units. 

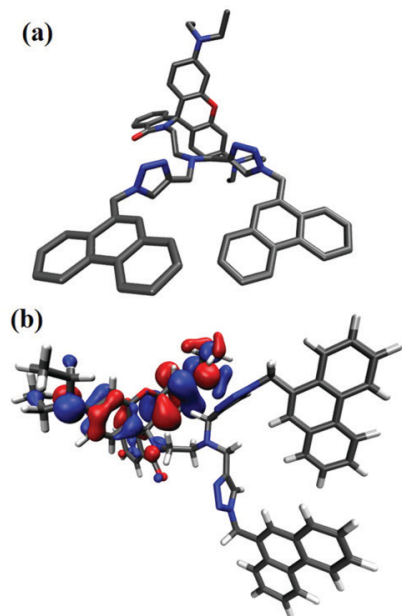

(c)
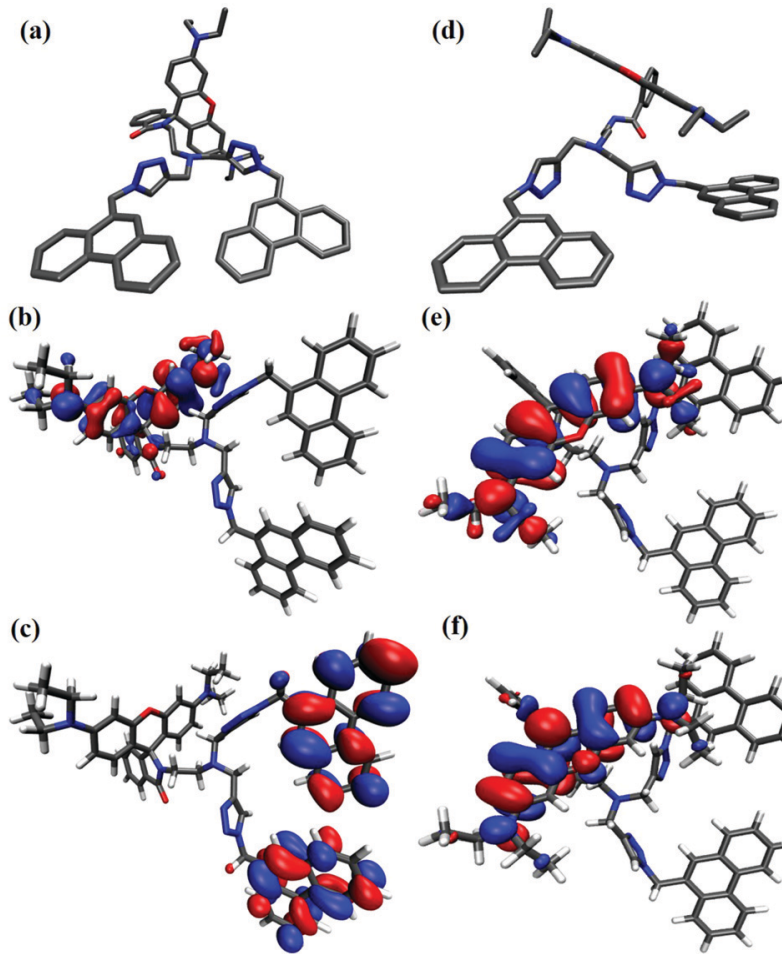

(e)

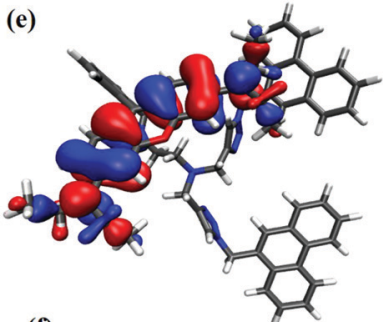

(f)

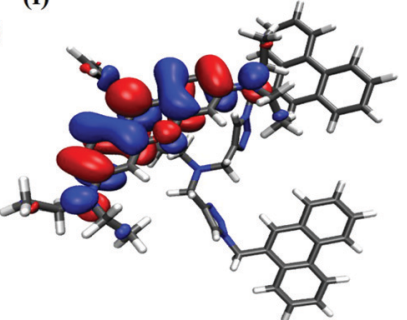

Fig. 8 DFT optimized structures of dyad $\mathbf{8}(\mathrm{a})$ and its $\mathbf{8}+\mathrm{H}^{+}$; protonated form (d); HOMO (b) and LUMO (c) isosurfaces of dyad $\mathbf{8}$ and protonated form HOMO (e) and LUMO (f) obtained at the $\omega B$ 97X-D3/def2-TZVP level. Plots were generated using ORBKIT, isovalue $=0.02 a_{0}{ }^{-3.54-57}$

\section{Quantum chemical calculations}

Dyad 8 and its protonated form have been optimized at the PBEh- $3 c^{54}$ level of density functional theory (DFT) using the Turbomole programme package (version 7.3) ${ }^{55}$ and COSMO $^{56}$ to implicitly include solvation effects (Fig. 8). Fig. 8 shows the HOMO and LUMO isosurfaces of dyad 8 and protonated $8+\mathrm{H}^{+}$ obtained at the $\omega$ B97X-D3 level. For 8, the HOMO is localized on the rhodamine structural motif (Fig. 8b), while the LUMO is delocalized over the two phenanthrene moieties (Fig. 8b). ${ }^{57}$ The degree of localization in the LUMO is governed by the amount of "exact" exchange included in the density functional approximation that is employed. In the case of PBE0 $(20 \%$ exact exchange), for example, the LUMO is fairly localized on the phenanthrene units. For protonated dyad $\left[8+\mathrm{H}^{+}\right]$, both HOMO and LUMO are localized on the rhodamine motif (Fig. 8, panels e and $\mathrm{f}$ ). A closer inspection reveals that the major difference between the two orbitals is given by the distribution of the nodes at the central pyran unit. Not very surprisingly, while the HOMO contains contributions from a conventional $\pi$-orbital located at the pyran moiety, the LUMO encompasses its $\pi^{*}$-orbital analogue.

The most useful values are likely acquired with the PBE0 functional which results in a HOMO-LUMO gap of $4.2 \mathrm{eV}$ for 8 and $3.10 \mathrm{eV}$ for $8+\mathrm{H}^{+}$. In general, the HOMO-LUMO gap decreases by roughly 1-1.5 eV when protonating the dyad. The front view of dyad $\mathbf{8}$ and its protonated form revealed a clear change in the orientation of the phenanthrene units caused by the opening of spirolactam ring of rhodamine B as expected (Fig. 8, panels a and d). The DFT optimized structures also showed an increased in the distance between the two phenanthrene units from $8.92 \AA$ for dyad 8, and $11.22 \AA$ for the protonated dyad, respectively. As the observed change in distance is not large, we can conclude that the orientational changes of phenanthrene units are responsible for the observed excimer emission decrease at acidic $\mathrm{pH}$ values.

\section{Analyte selectivity and photostability}

To assess the analyte selectivity of the dyad sensor, we performed selectivity studies in $\mathrm{THF}-\mathrm{H}_{2} \mathrm{O}$ mixture in $\mathrm{B}-\mathrm{R}$ buffer with metal ions typically present in biological systems or in other application-relevant environments. Thereby, always 10 equiv (10 fold excess; $50 \mu \mathrm{M})$ of different metal ions $\left(\mathrm{K}^{+}, \mathrm{Na}^{+}, \mathrm{Ca}^{2+}\right.$, $\mathrm{Ba}^{2+}, \mathrm{Mg}^{2+}, \mathrm{Cd}^{2+}, \mathrm{Zn}^{2+}, \mathrm{Co}^{2+}, \mathrm{Ni}^{2+}, \mathrm{Cu}^{2+}, \mathrm{Hg}^{2+}, \mathrm{Fe}^{2+}$, and $\mathrm{Fe}^{3+}$, $1.5 \mu \mathrm{L}$ of $\left.10^{-1} \mathrm{M}\right)$ were separately added to dyad solutions $(5 \mu \mathrm{M})$ and the resulting emission spectra obtained at $\lambda_{\text {Ex }}$ of $315 \mathrm{~nm}$ (phenanthrene excitation) and $560 \mathrm{~nm}$ (rhodamine excitation) were measured for each $\left[\right.$ Dyad $\left.+\mathrm{Metal}^{+}\right]$solution. These screening studies revealed no significant changes for any of these metal ions as highlighted in Fig. 9 (Fig. S20 ESI $\dagger$ ). We also performed selectivity and interaction studies of dyad 8 with different anions and selected amino acids (10 equiv; $1.5 \mu \mathrm{L}$ of $10^{-1} \mathrm{M}$ ). None of these anions or amino acids led to changes in the emission intensity of our dyad as shown in Fig S21 in the ESI. $\dagger$ These results underline the high selectivity of dyad 8 for protons/pH.

The advantage of using phenanthrene as a reference fluorophore follows from the photographs of the sensor solutions. The violet color of phenanthrene is visible at $\mathrm{pH} 7.5$ to 5.5 while the rhodamine signal is absent at pH 7.5 (Fig. 10; left). Thereby, dyad 8 can b always detected fluorometrically which would otherwise not feasible. An acidic $\mathrm{pH}$ of 5 or less is signaled by the appearance of the orange-red color of the rhodamine absorption and emission.

Other factors that govern the suitability of a sensor are its response time, reversibility and chemical and photochemical stability. To assess the reversibility and hence reusability of dyad 8, we ran $\mathrm{pH}$ cycles with 8 , varying the $\mathrm{pH}$ of dyad

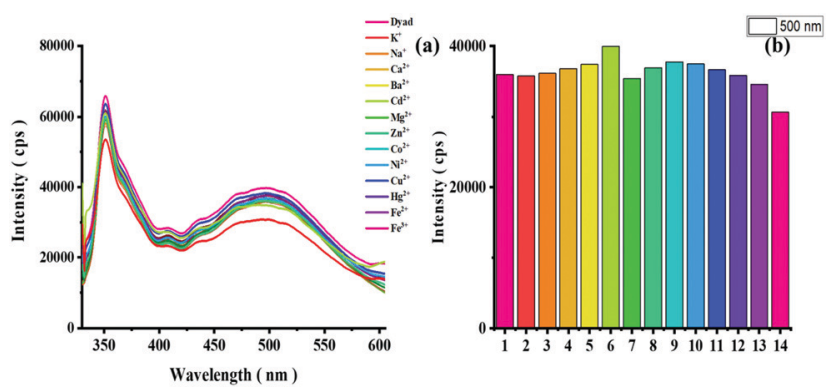

Fig. 9 (a) Emission spectra and (b) bar diagram of the selectivity studies of dyad 8 with the application-relevant metal ions $\mathrm{K}^{+}, \mathrm{Na}^{+}, \mathrm{Ca}^{2+}, \mathrm{Ba}^{2+}, \mathrm{Cd}^{2+}$, $\mathrm{Mg}^{2+}, \mathrm{Zn}^{2+}, \mathrm{Co}^{2+}, \mathrm{Ni}^{2+}, \mathrm{Cu}^{2+}, \mathrm{Hg}^{2+}, \mathrm{Fe}^{2+}$, and $\mathrm{Fe}^{3+}$ always separately adding 10 equiv. (10 fold excess) of the respective metal ion to dyad 8 $(5 \mu \mathrm{M})$. Excitation was at $\lambda_{\mathrm{Ex}}$ of $315 \mathrm{~nm}$ (phenanthrene). in $\mathrm{THF}-\mathrm{H}_{2} \mathrm{O}$ mixture (1:1) in $\mathrm{B}-\mathrm{R}$ buffer ( $\mathrm{pH} 7.0 ; 25 \mathrm{mM})$. 

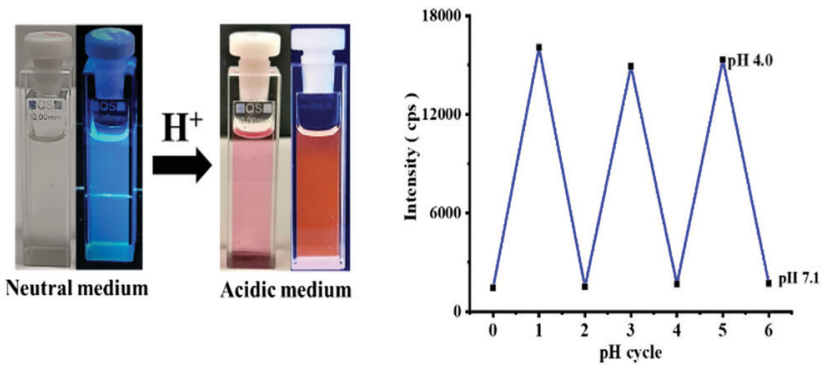

Fig. 10 (a) Color changes of the $\mathrm{pH}$ sensor 8 under UV light detected by naked eye at $\mathrm{pH} 7.0$ and $\mathrm{pH} 2.0$; (b) reversibility of the fluorescence response of dyad $\mathbf{8}$. All measurements were done with $5 \mu \mathrm{M}$ of dyad $\mathbf{8}$ dissolved in a THF- $\mathrm{H}_{2} \mathrm{O}$ mixture $(1: 1)$ in $\mathrm{B}-\mathrm{R}$ buffer $(\mathrm{pH} 7.0 ; 25 \mathrm{mM})$.

solutions from 7.0 to $\mathrm{pH} 4.0$ back and forth up to three times and measured the fluorescence intensity at $582 \mathrm{~nm}$ corresponding to the open ring form of rhodamine $\mathrm{B}\left(\lambda_{\mathrm{Ex}}=560 \mathrm{~nm}\right)$. These measurements did not reveal a loss in fluorescence after these $\mathrm{pH}$ cycles (Fig. 10; right). Moreover, the response times are very short, in the order of a few seconds. To determine the photostability of dyad 8, dyad solutions ( $5 \mu \mathrm{M}$; THF-water solution) of $\mathrm{pH} 7.2$ and $\mathrm{pH} 2$ were illuminated with a $450 \mathrm{~W}$ xenon lamp of a fluorometer for up to 420 mins and the emission spectra of $\mathbf{8}$ were recorded every 30 minutes, using an excitation wavelength of $315 \mathrm{~nm}$. The emission intensities at $350 \mathrm{~nm}$ and $500 \mathrm{~nm}$ at $\mathrm{pH} 7.2$ and $350 \mathrm{~nm}$ and $582 \mathrm{~nm}$ at $\mathrm{pH}$ 2.0 revealed only marginal changes, underlining the high photostability of our dyad (see ESI, $\dagger$ Fig. S22).

\section{Conclusion}

We designed and synthesized a new sensor dyad combining two $\mathrm{pH}$-insensitive phenanthrene fluorophores and one $\mathrm{pH}$-sensitive rhodamine $\mathrm{B}$ derivative in one molecule and spectroscopically assessed its $\mathrm{pH}$ responsivity in THF-water mixtures in in BrittonRobinson (B-R) buffer in the $\mathrm{pH}$ range of 7.5 to 1.0. These studies underline the advantage of our dyad sensor revealing three spectroscopically distinguishable emission bands at $351 \mathrm{~nm}$, $500 \mathrm{~nm}$, and $582 \mathrm{~nm}$ upon excitation at a single wavelength of $315 \mathrm{~nm}$, originating from the phenanthrene monomer, phenanthrene excimer and the rhodamine. In comparison to a simple OFF-ON sensor molecule like a fluorescent probe exploiting a photoinduced electron transfer (PET), utilization of the phenanthrene monomer emission or the combined monomer and excimer emission as the $\mathrm{pH}$-inert reference signal enables not only ratiometric measurements for analyte quantification but also the visualization of the dyad at all $\mathrm{pH}$ values, also at $\mathrm{pH}$ values $\geq 7.5$ where the rhodamine is in its ring-closed nonemissive spirolactam form. The use of two phenanthrene units provides more versatility regarding the choice of the reference signal, namely either the blue phenanthrene monomer emission or combined blue and green phenanthrene fluorescence. Screening studies with a series of biologically relevant metal ions underline the excellent selectivity of our $\mathrm{pH}$-responsive dyad.
In the future, we plan to improve the water solubility of our dyad sensor by introducing hydrophilic substituents such as a 2-chloro methane sulfonate substituent. Moreover, to bind the dyad to different types of nanoparticles acting as carriers, this substituent can be used in conjunction with an additional reactive carboxylic group introduced into the rhodamine part of the dyad. For the simple application in aqueous environments dyad $\mathbf{8}$ without the need for chemical modification, compound $\mathbf{8}$ can be encapsulated in mesoporous silica nanoparticles ${ }^{58}$ or polymer-based nanoparticles like PEBBLE ${ }^{59}$ type nanoparticles. This provides also a simple signal enhancement strategy and enables, e.g. a straightforward approach to combine dyad 8 with targeting bioligand like biomarker-specific antibodies. ${ }^{60}$ Furthermore, the dye can also be integrated into a D4 hydrogel yielding a $\mathrm{pH}$-responsive sensor film as previously done for water-insoluble BODIPY dyes. ${ }^{52}$

\section{Conflicts of interest}

There are no conflicts to declare.

\section{Acknowledgements}

P. S. acknowledges the Adolf Marten fellowship of the Federal Institute for Material Research and Testing (BAM), Berlin, Germany. F. W. gratefully acknowledges the Deutsche Forschungsgemeinschaft for financial support through research grant PA 1360/16-1. The North-German Supercomputing Alliance (Norddeutscher Verbund für Hoch-und Höchstleistungsrechnen) is acknowledged for providing computational resources. We are also grateful for support by the NMR and mass spectrometry facilities of Freie University Berlin measuring the NMR and MS spectra of the compounds prepared.

\section{Notes and references}

1 A. Steinegger, O. S. Wolfbeis and S. M. Borisov, Chem. Rev., 2020, 120, 12357-12489.

2 H. Izumi, T. Torigoe, H. Ishiguchi, H. Uramoto, Y. Yoshida, M. Tanabe, T. Ise, T. Murakami, T. Yoshida, M. Nomoto and K. Kohno, Cancer Treat. Rev., 2003, 29, 541-549.

3 M. Chesler, J. O. Brien, A. Zappala, F. Cicirata and L. C. Barrio, Physiol. Rev., 2008, 1183-1221.

4 A. M. Paradiso, R. Y. Tsien and T. E. Machen, Nature, 1987, 325, 447-450.

5 Y. Yue, F. Huo, S. Lee, C. Yin and J. Yoon, Analyst., 2017, 142, 30-41.

6 J. R. Casey, S. Grinstein and J. Orlowski, Cell Biol., 2010, 11, 50-61.

7 I. Mellman, R. Fuchs and A. Helenius, Annu. Rev. Biochem., 1986, 55, 663-700.

8 R. Martinez-Zaguilan, E. A. Seftor, R. E. Seftor, Y. W. Chu, R. J. Gillies and M. J. Hendrix, Clin. Exp. Metastasis, 1996, 14, 176-186. 
9 S. Kornfeld and I. Mellman, Annu. Rev. Cell Biol., 1989, 5, 483-525.

10 E. J. Blott and G. M. Griffiths, Secretory lysosomes, Nat. Rev. Mol. Cell Biol., 2002, 3, 122-131.

11 J. Stinchcombe, G. Bossi and G. M. Griffiths, Science, 2004, 305, 55-59.

12 M. Schindler, S. Grabski, E. Hoff and S. M. Simon, Biochemistry, 1996, 35, 2811-2817.

13 R. T. Kennedy, L. Huang and C. A. Aspinwall, J. Am. Chem. Soc., 1996, 118, 1795-1796.

14 R. Martínez-Zaguilán, B. F. Chinnock, S. Wald-Hopkins, M. Bernas, D. Way, M. Weinand, M. H. Witte and R. J. Gillies, Cell. Physiol. Biochem., 1996, 6, 169-184.

15 H. Galster, pH Measurement: Fundamentals, Methods, Applications, and Instrumentation. VCH, New York. 1991.

16 F. B. M. Suah, M. Ahmad and M. N. Taib, Sens. Actuators, B, 2003, 90, 182-188.

17 J. Qi, D. Liu, X. Liu, S. Guan, F. Shi, H. Chang, H. He and G. Yang, Anal. Chem., 2015, 87, 5897-5904.

18 J. Han and K. Burgess, Chem. Rev., 2010, 110, 2709-2728.

19 S. Charier, O. Ruel, J. B. Baudin, D. Alcor, J. F. Allemand, A. Meglio and L. Jullien, Angew. Chem., Int. Ed., 2004, 43, 4785-4788.

20 M. Su, Y. Liu, H. Ma, Q. Ma, Z. Wang, J. Yang and M. Wang, Chem. Commun., 2001, 960-961.

21 A. Lobnik, I. Oehme, I. Murkovic and O. S. Wolfbeis, Anal. Chim. Acta, 1998, 367, 159-165.

22 D. A. Nivens, M. V. Schiza and S. M. Angel, Talanta, 2002, 58, 543-550.

23 J. Ji and Z. Rosenzweig, Anal. Chim. Acta, 1999, 397, 93-102.

24 O. S. Wolfbeis, Anal. Chem., 2000, 72, 81-89.

25 D. Aigner, B. Ungerböck, T. Mayr, R. Saf, I. Klimant and S. M. Borisov, J. Mater. Chem. C, 2013, 1, 5685-5693.

26 K. H. Knauer and R. Gleiter, Angew. Chem., Int. Ed. Engl., 1977, 16, 113.

27 X. He, F. Ding, W. Xua, C. Xua, Y. Lia, Y. Qian, S. Zhao, H. Chen and J. Shen, Anal. Chim. Acta, 2020, 1127, 29-38.

28 Z. Ding, G. Liu and J. Hu, Biomacromolecules, 2020, 21, 3436-3446.

29 J. Wang, X. Wang, X. Pan, W. Pan, Y. Li, X. Liang and X. Sun, Microchim. Acta, 2020, 187, 330.

30 J. Wang, S. Xia, J. Bi, Y. Zhang, M. Fang, R. L. Luck, Y. Zeng, T.-H. Chen, H. M. Lee and H. Liu, J. Mater. Chem. B, 2019, 7, 198-209.

31 Y. Yang, Q. Zhao, W. Feng and F. Li, Chem. Rev., 2013, 113, 192-270.

32 Y. E. Koo Lee, R. Kopelman and R. Smith, Annu. Rev. Anal. Chem., 2009, 2, 57-76.

33 J. Chao, Y. Liu, J. Sun, L. Fan, Y. Zhang, H. Tong and Z. Li, Sens. Actuators, B, 2015, 221, 427-433.
34 A. Arroyo-Pieck, D. Araiza-Olivera and J. Peon, Chem. Plus. Chem., 2018, 83, 1097-1108.

35 D. Wencel, T. Abel and C. McDonagh, Anal. Chem., 2014, 86, 15-29.

36 M. S. Briggs, D. D. Burns, M. E. Cooper and S. J. Gregory, Chem. Commun., 2000, 2323-2324.

37 J. E. Mathejczyk, J. Pauli, C. Dullin, U. Resch-Genger, F. Alves and J. Napp, J. Biomed. Opt., 2012, 17, 076028.

38 C. Wang, S. Otto, M. Dorn, K. Heinze and U. Resch-Genger, Anal. Chem., 2019, 91, 2337-2344.

39 M. Meldal and C. Wenzel Tornøe, Cu-Catalyzed AzideAlkyne Cycloaddition, Chem. Rev., 2008, 108, 2952-3015.

40 X. Chen, T. Pradhan, F. Wang, J. S. Kim and J. Yoon, Chem. Rev., 2012, 112, 1910-1956.

41 Z. Li, Y. Song, Y. Yang, L. Yang, X. Huang, J. Han and S. Han, Chem. Sci., 2012, 3, 2941-2948.

42 H. Montenegro, M. Di Paolo, D. Capdevila, P. F. Aramendía and M. L. Bossi, Photochem. Photobiol. Sci., 2012, 11, 1081-1086.

43 M. Tian, X. Peng, J. Fan, J. Wang and S. Sun, Dyes Pigm., 2012, 95, 112-115.

44 Z. Hu, M. Li, M. Liu, W. Zhuang and G. Li, Dyes Pigm., 2013, 96, 71-75.

45 H. S. Lv, J. Liu, B. X. Zhao and J. Y. Miao, Sens. Actuators, B, 2013, 177, 956-963.

46 H. Beens, H. Knibbe and A. Weller, J. Chem. Phys., 1967, 47, 1183-1184.

47 E. M. S. Castanheira and J. M. G. Martinho, J. Photochem. Photobiol., A, 1994, 80, 151-156.

48 F. D. Lewis and E. L. Burch, J. Photochem. Photobiol., A, 1996, 96, 19-23.

49 I. B. Berlman, Handbook of Fluorescence Spectra of Aromatic Molecules, Academic Press Inc., New York. NY, 1965.

50 W. R. Dawson and M. W. Windsor, J. Phys. Chem., 1968, 72, 3251-3260.

51 H. T. S. Britton and R. A. Robinson, Chem. Soc., 1931, 1456.

52 S. Radunz, E. Andresen, C. Würth, A. Koerdt, H. R. Tschiche and U. Resch-Genger, Anal. Chem., 2019, 91, 7756-7764.

53 M. Taniguchi and J. S. Lindsey, Photochem. Photobiol., 2018, 94, 290-327.

54 PBEh-3c, DOI: 10.1063/1.4927476.

55 TM, DOI: 10.1016/0009-2614(89)85118-8.

56 COSMO, DOI: 10.1039/P29930000799.

57 ORBKIT, DOI: 10.1002/jcc.24358.

58 L. Exbrayat, S. Salaluk, M. Uebel, R. Jenjob, B. Rameau, K. Koynov, K. Landfester, M. Rohwerder and D. Crespy, ACS Appl. Nano Mater., 2019, 2, 812-818.

59 D. Si, T. Epstein, Y.-E. Koo Lee and R. Kopelman, Anal. Chem., 2012, 84, 978-986.

60 T. Behnke, J. E. Mathejczyk, R. Brehm, C. Würth, F. R. Gomes, C. Dullin, J. Napp, F. Alves and U. Resch-Genger, Biomaterials, 2013, 34, 160-170. 